\title{
To Study the Evolution of Private Gardens of the Bridges
}

\author{
Yang Li
}

Art Institute of Suzhou University, 215123, China

Keywords: private garden; bridge; bridge evolution.

\begin{abstract}
The bridge is different from the private gardens royal gardens of the grand. Garden tin image than road is obvious, but does not mean it as grand bridge. And because they are carefully sited, adjust measures to local conditions, and the nature harmonious beautiful modelling, become the symbol of the garden, the focus of the landscape. Almost indispensable in the garden. By collecting refer to ancient stone, wall paintings, prints and other works and a large number of ancient documents, and with full traceability, field landscape mapping, investigation and analysis of landscape set law of tin, comprehensive research of private garden bridge.
\end{abstract}

\section{The three jin and the northern and southern dynasties}

Since the eastern Han dynasty last years, our country has entered a war frequently turbulent times. Long-term unrest and war, as the economy and culture in the north has brought serious damage. The south has experienced three soochow, eastern jin and song, qi, liang and Chen dynasties after the change, but compared with the central plains region, is still seems relatively stable. So large Numbers of people migrate to the south to avoid war. With the influx of large population, not only brought the jiangnan labor and advanced production technology, and the fusion of native northern cremation and jiangnan literati, also promoted the development of the local culture. Starting from this period, the jiangnan region gradually prosperous, and thus provides conditions to the construction of large mansions in Suzhou. Such as the eastern Jin period SiTuWang perishes and customary wang brothers; had to build a large don't industry in outskirts of huqiu, is said to have two houses built around the mountain, almost wrapped the whole hill, so that people are "all hid good peak, don't teach you view the human", its scale, beyond people's imagination. And as Liang city internal security WeiQing monk Lu hae-chan, Suzhou secretariat of Gu Yanxian mansions, size not only, but also a bamboo landscape, its internal environment is very elegant.

Long-term unrest in Wei Jin southern and northern dynasties, it is thought, culture and art have a major change in time. To avoid conflict and perched on hills, is also very common during this period, this is the so-called "habitat late hermit", which makes people has a more profound cognition on natural landscape. Chinese landscape literature and landscape painting, all roughly mature in this period. People give praise, in the form of landscape poetry in the form of landscape painting to describe, actually represent the ideal in nature. The same reappear, of course, more available was originally a natural thing in the world of flowers and trees as elements such as the collection of according to own understanding and pursuit, reshape back between the houses. So if "natural" landscape garden, began to become people yearning. Cause the change of landscape creation, garden bridge can be seen as the formation of art. Initially established in the present the basic principle of the natural landscape, garden of phasing out the production, hunting, and treat garden mainly as ornamental art to taste more attention to the beauty of nature. Garden miniaturization began to look up, private gardens at this time also appeared. With the development of garden miniaturization, generalization, reappearance piled mountain forest artistic conception of freehand brushwork in traditional Chinese gardening technique dominates. Creative ideas and methods for small, delicate, elegant and trend.

\section{The sui, tang, period}

From the Sui dynasty to the tang dynasty, three hundred years, jiangnan society is stable, as the Grand Canal, south economic center, the jiangnan camp boom. Then some jiangnan garrison giants 
groups, and to promote the construction of the jiangnan gardens, provided the conditions. The southern tip of Hangzhou, from the canal to the north of the Yellow River interchange BianZhou, appeared numerous bustling commercial city, the river become supplies and talents convergence place. Suzhou rich for a long time, the opening of the grand canal to its benefit. Enter the peacetime, the more rapid economic growth and cultural development. "Said:" Wu Jun shigeo of tang dynasty, Sue, solid for Zhejiang right first." Build YuanJu is given priority to with natural landscape, pursue Shan, formed one of the garden style. Although the independent regime in the five dynasties and ten states make unified China caused a split, economic damage, but the jiangnan has a role in promoting economic development, so the lords of gardening copiously.

Sui and tang dynasties, the gardening quantity, scale, type diversity, but also tell from the gardening art reached a new level, directly involved in the literati gardening activities, thus the gardening art and poem, the words. Landscape for the "garden" in the main, the role of the bridge are interspersed with, looming, contrast and set off, due to borrow is greater than the string landscape functions, usually like to decorate, the bridge island make the person can't be clear at a glance, for example: from the sui dynasty was discovered in 1982 tianshui stone, screen the sarcophagus bed screen number 7 has hill bridge railings, 6 were described stone couples drink figure. Jehiel mountain type hall there was a building there is a bridge over the railing of Sui ZhanZiQian YouChun beings "Zhu Qiao over the stream. At the same time, the emergence of wang Wei's "rim Sichuan don't industry" marks the compatibility of poetry and new literati garden appear truly. Make full use of the natural conditions, just like a picture of quietly elegant is free and natural landscape picture scroll. The original in the guanzhong sites' disposition "rim sichuan don't industry" figure of a bridge near the Wen Xing pavilion is like concealed in the mountains, across the bridge into the ridge below apricot pavilion scenery natural connection, like a picture of a beautiful landscape picture scroll. Of dunhuang murals in the sui dynasty three bound wat, wat, top one word wrap around the west painting Mr Duo (du ǒ) with Mr Fukuda Bunsen JingBian (one of) the emergence of a bridge, the bridge shape, baluster, column board and black railings stigma, stigma into peach shape. Connected to a building, the building is located platform. The bridge connected to the platform railing. Building on the right side of planting trees. In addition, in the sui dynasty three "wat, wat, top herringbone JingBian wrap around the east painting method of China, the universal door (one of) and the universal gate chapter of (2) China JingBian, all have the same image of the bridge, only the latter railings, railing stigma for scarlet, column board is black.

With the development of private garden, small garden has been welcomed by more people, the small pool in the garden of special spoiled. Bai juyi in fulfillment of Luoyang road lane house, as a representative of the home garden style of this period. According to bai "pool last" and the poem records, garden and curtilage base, a total of 17 acres, curtilage one-third, water accounts for one 5, one 9, the other is island, bridge, road, trees. Garden layout is centered on the pool, pool set three island, the island pavilion, two bridge with island.... "bai juyi operates the garden for more than a decade and its landscape have high taste of elegant, is an example of the teachers of the small and medium-sized home garden.

Tang to song aesthetic measure tends to "small" and "private", emphasize the individual inner mind, more is to the spirit of self satisfaction and intoxicated; make beauty and personal daily life are closely linked, indulged in gardening style of play, mainly in the pursuit of formal beauty. Start with small in see big gardening theory and technique, create change rich art space.

\section{Two song period}

Compared with the tang dynasty, song dynasty literati in regime relative increase in the position, function, culture, education, science and technology on an unprecedented prosperous picture. Garden is in the tang dynasty on the basis of further extends to deep local urban and social development. Since the late tang dynasty, literati gardening gradually into the atmosphere. The landscape change mansions traditional landscape of that kind of pursuit of old habits, pageantry, introducing reclusion on simplicity and elegant city in the house. To this song, began to become very common. Gardening 
activities to an all-time high, with literature, poems, especially the development of the art of painting, deepening the understanding of natural beauty, the garden can be more widely and people's life, like lee ge fei's 19 were carried by the luoyang gardens, the author through the gardens, half or the literati garden and villa. The most thriving northern song dynasty capital, the capital of song dynasty and xiking Luoyang gardens. The southern song linan, private garden around the inside and outside the city. At pingkiang, jiangnan more economic boom, at this time (now Suzhou) is Francisco screen town of southern song dynasty, tang dynasty when the private garden in the city can take an examination of only two, three, and has more than 10 in the song dynasty. Like Su Shunqin surging wave pavilion, Zhu Changwen "LePu" and so on, belong to the garden. Is still is a landscape garden flowers and trees, but the purport of the big change. They are the garden as a hermit mountain forest to send chest YuFen, thus seek more trees open in the form. Garden built "jia oratory", "hill", "the inkwell pavilion", "pen stream", "called implicit bridge", "west jian", "western garden", "west hill" all wins, campus lush trees, ancient packing ke, is very elegant. Another strip nursery and cultivation of four famous flowers, daily herbs and green vegetable fresh fruit, not only to serve guest entertainment, and filling and garden cultivation in person, so as to realize the ideal he retired.

Literati painters reveling in landscapes, apply poetry to the botanical garden, the pursuit of message, detachment of the artistic conception; Put on rock garden in zhongshan pool was meant to habitat, the formation of literary conception mountain and water garden art, the freehand brushwork in traditional Chinese literati painters to participate in gardening, and more to landscape painting, poetry as the theme, to draw a scene, the scene show; Moral emotion in scene, in the form to conception, with vivid form; Architecture combining poetic couplet plaques and gardens. Suzhou is like zhu meng "paradise" luxurious mansion garden. Zhu meng in pan gate curtilage up a hall with high ceiling, wide park pool. It's said that the "paradise", has "the temple of god clouds", "good temples", "picket division temple", "double festival hall", "royal RongDian", "the royal pavilion", "fan xiang floor", "zigzag bridge", "sweet pavilion", such as construction, Jin Mingchi for plotting about northern song dynasty city bian city named "play for the underlying scene graph ZhongYuan wall around the pond, mastery of arch bridge water in the pool house. Plastic beauty diversity is a feature of song dynasty garden architecture, the song we can glimpse in the painting, such as zhao li figure banners, Castle Peak green water in an arch bridge, bridge is a smooth parabola and bridge deck paved with rung, modelling of soft beauty.

Wang Ximeng in Trinidad Jiang Shantu of painted pavilions, Bridges, pavilions, cabinet, and other forms of buildings is also very colorful. Only the style of the bridge is presented, the pavilion bridge, girder bridge and so on, in the north and south song dynasties literati, theme park, can pay attention to the combination of architecture and natural environment, landscape scale becomes more and more small, space change increasingly rich, the scenery is increasingly delicate, garden has become the "three-dimensional paintings, solidification of poetry". The lotus club figure of northern song dynasty li kung-lin south river waters have a delicate little bridge, size is small, but the four corners of the railing and stigma, from soup to nuts. Low bridge, combined with the modelling of small Bridges. Duo mountain water management, performance lives mountain stream of pool. Point of view the pavilion, built, usually go there on special trip for Bridges, winding path leading to a secluded spot, ting corridor construction in accordance with the scene, loose free layout. Surprisingly natural interest.

Bei song personally designed gen (Ge ǹ) yue broke through tw o since the Qin and Han dynasties "a pool of three mountains" conventions, with the theme of landscape creation. Building has the dual function of use and ornamental, garden design in conception, to landscape painting, to appraise for the landscape poetry theme, poems, and the garden are garden painting. This according to gardening art understanding of landscape and living needs, adjust measures to local conditions and true and picturesque garden, mountain and water garden has become a freehand brushwork in traditional Chinese. 


\section{Conclusion}

Architecture is the most unstable landscape change factor, the changes of The Times value orient ation and aesthetic fashion, and the first through the building, along with the change of The Times, cultural heritage and alienation, of the emergence of bud of private gardens, garden has experienced the stages of change process. Reveals people's thought idea, society and the change of the social ec onomy, also brought a certain degree of influence to face of the garden. Garden bridge, material in $t$ he form of even the role has changed dramatically.

\section{Acknowledgments}

Graduate student research innovation project (CXZZ12_0800); Jiangsu university advantage disciplines construction engineering projects (PAPD).

\section{References}

[1] (clear) Li Mingwan Tan Junpei repair, the Chinese local Chronicles integration (M), government record copy (word), Suzhou, Nanjing: Jiangsu ancient books publishing house, Shanghai bookstore, bashu publishing house, 1990.

[2] Sima qian from han, song pei Yin set, tang SiMaZhen somalia's government, tang zhang feast justice, historical records (M) the first volume, volume 1 to 7, 218, Beijing: published by zhonghua book company, 1959, the first, second edition in November 1982, 1982 (11).

[3] Cao Lindi, Chinese garden art (M), Taiyuan, Shanxi education press, 2001 (01).

[4] Tang whistling arrow, Zhenyu Huang, Pan Xiaolan compiled, ancient Chinese architecture and gardens (M), Beijing: tourism education press, 2003 (8).

[5] Jiang Hong, Zhu Zina editor, Ye Wanzhong, tang, the dictionary of Suzhou, Suzhou: Suzhou university press, 1999 (9). 